\title{
Effects of an Integrated Psycho-Pedagogical and Social Program on Development of Behaviour Skills for Children with Autism Spectrum Disorder
}

\author{
Manuel Ojea Rúa ${ }^{1 *}$ and Andrea Vieira Vázquez ${ }^{2}$ \\ ${ }^{1}$ Department of Analysis and Psychosocial- Educational Intervention, University of Vigo, Spain \\ ${ }^{2}$ Psychologist of Autism Association, Spain
}

Submission: December 19, 2017; Published: January 08, 2018

*Corresponding author: Manuel Ojea Rúa, Department of Analysis and Psychosocial-Educational Intervention, University of Vigo, Spain, Email: moxea@uvigo.es

\begin{abstract}
This study aimed to show if an integrated psycho- pedagogical program, structured according to the social mediation model would result in greater Flexibility and functional activity of behaviour skills in individuals with Autism Spectrum Disorder (ASD). An experimental research design pre- tests (1) - post-test (2) was realized. A total of 14 children with ASD participated in the intervention program specific ad hoc applied during two years. Results found through comparative analysis Friedman Test and Multivariate Tests Within- Subjects Effects, showed that the intensive intervention improved children's behaviour and their functional adaptation to the context and, in conclusion, social live and inclusion improved.
\end{abstract}

Keywords: Autism Spectrum Disorder; Behavioral Skills; Social Abilities; Social Mediation

\section{Introduction}

People with Autism Spectrum Disorder (ASD) are defined by the International Classification of Mental Disorders (American Psychiatric Association, 2013) [1] as a continuum of basic needs in two development dimensions: communication and social interaction, and behavioral areas. Frith [2], Brandwein et al. [3] and Kimhi et al. [4] also show that this set of diagnostic symptoms is related to the particular perceptual processing of information, characterized by the high selection of stimuli in evaluating experiences both internally and externally, not only analyzing contextual processes, but with response and functional behavior in the environment also being influenced. These limitations involve deficits in the learning of flexible and adapted behavior, which allows the social response to be specified in different everyday situations, meaning the individual action in the social context is wrong or limited and there is a high risk of social exclusion in social interaction with peers [5]. Even when behavioral kinds are learned, the adjustment of responses to the partner's requirements may also be limited $[6,7]$.

Ojea [8] says these diagnostic features are not an isolated process, limited to observable behavior, but rather share the functioning interrelation of the cognitive-perceptive system, in which all neuropsychological processes are interrelated as a whole. In didactic methodology, designing specific behavioral development programs is fundamental, although learning the programs should not be limited to teaching isolated, disconnected behaviors but rather the program structure must respond to two fundamental basic aspects:

a) Systemic psychological interaction of one's own cognitive-perceptive dimensions; and

b) Practical intervention methodology based on the principles of social mediation.

With regards to the first aspect, systemic psychological interaction requires all interrelated neuropsychological processes to be activated about learning, which involves the cognitive learning practices that include attitudinal, emotional, motivational, behavioral and motor dimensions. Lee and Vargo [9] used interrelated physical activity to improve the development of social skills through movement. Likewise, López, Moreno-Rodríguez, Alcover, Garrote and Sánchez [10] provided arguments for a motor teaching methodology to improve 
behavioral and social development.

Chou, Lee and Feng [11] used the art approach to experiment with learned behaviors, exploring body movement elements such as the shape or rhythms to establish social adaptation. It is worth noting that Nelson, Paul, Johnston and Kidder [12] researched dance and creativity as basic instruments to enhance the development of social skills and communication. Bagaiolo et al. [13], Cardinal et al. [14] and Hughes and Yakubova [15] reported positive effects of video modeling as a method by which students learn new behaviors of viewing the skill modeled, including better effectiveness acquisition and generalization of social skills. With regards to practical intervention, this assumes that the interactive practices performed in the context should acquire functional understanding. Although there are different kinds of intervention models, the efficacy of a social mediation methodology has been evinced; this methodology consists of applying and assessing techniques for development and improvement of behavior in the natural environment, as well as carrying out the proposed activities within the social context along with peers, in order to promote social interaction and avoid social exclusion. Social mediation uses cooperation and coteaching among the intervening factors in the educational process through specific training and coordination: family, teachers and peers, with extensive research showing effectiveness [16-20].

Furthermore, this study aims to unite both aspects in an integrated specific functional program for developing behavioral skills designed ad hoc to implement based parent-mediated behavioral intervention, with the following general goal:

I. To improve the children's flexible and functional behavior through behavioral music, video-modeling, psychomotor, dance, art, theater, role-playing and graphic plastic programs in integrating social skills.

To program an action-research methodology and involve family, teachers and peers in designing the interactive style intervention. Each session is structured in the following successive learning steps:

a) Facilitate a description of the social behavior to be improved.

b) Integration-observation of target behavior through video modeling using a pre-selected musical background.

c) Movement-psychomotricity rhythmic reproduction of Table1: Distribution of the participants.

\begin{tabular}{|c|c|c|c|c|c|}
\hline \multicolumn{5}{|c|}{ Age } & \multirow{2}{*}{ Total } \\
\hline & & $7-10$ years & 11-14 years & $15-18$ years & \\
\hline \multirow{3}{*}{ Diagnosis } & ASD1 & 2 & 1 & 1 & 4 \\
\hline & ASD2 & 2 & 2 & 2 & 6 \\
\hline & ASD3 & 1 & 2 & 1 & 4 \\
\hline Total & 5 & 5 & 4 & 14 & Total \\
\hline
\end{tabular}

music by free corporal dance movements.

d) Graphic reproduction by association of movements with shapes, colors, lines or writing.

e) Concept synthesis: oral expression-representation of learned behavior through theater.

f) Discrimination-selection-generalization of repertoire behavior and generalization of different stimuli and settings by role-playing within peers' relationships.

g) Peers, educators and parents receive hands-on intervention training to carry out the intensive program for support for parents, professionals and peers in order to develop their planned capacities.

h) Behavioral action in real situations with peerseducators-parents-mediated support, engaging experiences in natural settings.

i) Continuous assessment of applied behavior.

j) Improvements program according the process of assessing involvement of the specific needs.

\section{Hypothesis:}

Interaction of the psychological perceptive-cognitive experiences through interactions and relationships with parents, professionals and peers, improving behavior and striving for social inclusion of individuals with ASD.

\section{Method}

\section{Design}

The design is based on an experimental model of 1 group with 3 successive measures: pre-test - post-tests (1) - post-tests (2), which a specific ad hoc individual program was applied to improve the development of integrated behavioral skills $\left(A_{1}\right.$ : base line - B: program - $A_{2}$ : development- $A_{3}$ : development.

\section{Participants}

A total of 14 children with a specific diagnosis of ASD of different levels (1, 2 and 3), between 7 and 18 years of age, belonging the Social Communication Disorders Association of Ourense (Spain), that are in several province schools, whose distribution can be seen in Table 1 . system in the learning of behavior skills, integrated in real-life 
Diagnosis*Age: Frequencies.

\section{Variables}

Study's control of the behavioral dimensions has been analyzed by two variables included in the Autism Spectrum Inventory [21]:

i. Variable Flexibility that measures the level of behavior adaptation in the environment, and

ii. Variable Activity or functional sense and understanding of action carried out.

Three steps were intertwined corresponding with three measures in both variables: Flexibility 1, 2, 3 and 1, 2, 3. Step 1 each child have been assessed before starting the intervention to establish adapted ad hoc program. Step 2 and 3 was to know the level program effectiveness and, therefore, the children's individual developmental. The child's behaviors level in both variables was related to participants diagnosis level (variable: Diagnosis) and age range (variable: Age). Diagnosis level are classified to three degrees $(1,2,3$ level) by Diagnosis and Statistical Manual of Mental Disorders [1]. Age rank was defined into three intervals: (1) 7-18 years, (2) 11-14 years, (3) 15-18 years.

\section{Procedure}

After obtaining informed consent from the parents, the research was developed for 2 years in two weekly sessions, one individual session and another to the peer group, each session lasted $60 \mathrm{~min}$. Three phases were structured. Phase 1 included the pre-test analysis and the program design according children's assessments. Educators and parents were trained in the specific intervention. After 12 months, the Phase 2 second post-test analysis was carried out, which the program effectiveness was Table 2:Frequencies $\left({ }^{a}\right)$ evolution*diagnosis and age.

\begin{tabular}{|c|c|c|c|c|c|c|c|c|c|c|c|c|c|c|c|c|c|c|c|c|c|c|c|c|c|c|c|c|c|c|c|}
\hline \multicolumn{32}{|c|}{ SUM } \\
\hline \multirow[t]{2}{*}{ Level } & \multirow[t]{2}{*}{ Age } & \multicolumn{5}{|c|}{ Flexibility1 } & \multicolumn{5}{|c|}{ Flexibility2 } & \multicolumn{5}{|c|}{ Flexibility3 } & \multicolumn{5}{|c|}{ Activity 1} & \multicolumn{5}{|c|}{ Activity2 } & \multicolumn{5}{|c|}{ Activity3 } \\
\hline & & 0 & 1 & 2 & 3 & 4 & 0 & 1 & 2 & 3 & 4 & 0 & 1 & 2 & 3 & 4 & 0 & 1 & 2 & 3 & 4 & 0 & 1 & 2 & 3 & 4 & $\mathbf{0}$ & 1 & 2 & 3 & 4 \\
\hline ASD1 & 7- & & & & & & & & & & & & & & & & & & & & & & & & & & & & & & \\
\hline \multirow[t]{3}{*}{10} & 2 & & & & & & & 2 & & & & & & 1 & 1 & 1 & 1 & & & & & & 2 & & & & & & 1 & 1 & \\
\hline & $11-14$ & & 1 & & & & & & 1 & & & & & & & 1 & & 1 & & & & & & 1 & & & & & & 1 & \\
\hline & $15-18$ & & 1 & & & & & & 1 & & & & & & & 1 & 1 & & & & & & 1 & & & & & & 1 & & \\
\hline ASD2 & 7- & & & & & & & & & & & & & & & & & & & & & & & & & & & & & & \\
\hline \multirow[t]{3}{*}{10} & 1 & 1 & & & & & 1 & 1 & . & & & & 1 & 1 & & 1 & 1 & & & & & 1 & 1 & & & & & 1 & 1 & & \\
\hline & $11-14$ & & 2 & & & & & & 2 & & & & & & 2 & & & 2 & & & & & 1 & 1 & & & & & 1 & 1 & \\
\hline & $15-18$ & & 2 & & & & & 1 & 1 & & & & & 2 & & & 1 & 1 & & & & & 1 & 1 & & & & & 2 & & \\
\hline ASD3 & 7- & & & & & & & & & & & & & & & & & & & & & & & & & & & & & & \\
\hline \multirow[t]{3}{*}{10} & 1 & & & & & & 1 & & & & & & 1 & & & 1 & & & & & & & 1 & & & & & 1 & & & \\
\hline & $11-14$ & 1 & 1 & & & & & 2 & & & & & 1 & 1 & & & 1 & 1 & & & & & 2 & & & & & & 2 & & \\
\hline & $15-18$ & 1 & & & & & 1 & & & & & & 1 & & & & 1 & & & & & & 1 & & & & & 1 & & & \\
\hline
\end{tabular}

evaluated. Changes and adjusting in the program were made according to the assessment data. Finally, 12 months later, Phase 3 was completed with the post-test measure to compare the successive data in the selected variables. During the all period, the educators-parents-child interaction is continued to learn and practice under the specialist's support to promote the program implementation.

\section{Data analysis}

Data was analyzed using the following statistics:

a) The comparative measure for $k$ related samples of Friedman Test to compare the pre- intervention- postinterventions in the Flexibility y Activity variables and, consequently, assess the effectiveness of the program, and

b) One analysis of Multivariate Tests Within-Subjects Effects was conducted to compare the data evolution in the categorical variable Factor 1 (Flexibility 1,2,3 + Activity 1,2,3 intersection) and the relationship to the Diagnosis and Age variables and their intersection.

\section{Results}

Results showed that the intensive intervention improved children's behavior of a global perspective by allowing a flexible behavior and their functional adaptation to the context. The data are described following the three sections:

Indeed, the scores frequencies into the successive measures; Flexibility 1,2,3 y Activity 1,2,3, grouped according to the Diagnosis and Age variables is observed in Table 2. The participants have shown improvement in advanced adaptive flexibility and activity sense, as well as at the different levels of Diagnosis and Age.

\section{Frequencies of direct scores}

aMeasures (“0”: very low, “1”: low, "2": middle, "3": high, “4”: very high). 


\section{Psychology and Behavioral Science International Journal}

\section{Descriptive analysis}

Preliminary statistical analysis was indicated in Table 3. In general, students improved on the treatment objectives from

Table 3: Descriptive statistics. pre-test (Flexibility 1: $\mu=, 57 ; \sigma=, 51$ and Activity $1: \mu=, 50 ; \sigma=, 51$ ) compared to post-test (Flexibility $3: \mu=2,50 ; \sigma=, 94$ and Activity 3: $\mu=2,35 ; \sigma=, 74$ ).

\begin{tabular}{|c|c|c|c|c|c|}
\hline & N & Mean & Std. Deviation & Minimum & Maximum \\
\hline Flexibility1 & 14 &, 57 &, 51 &, 00 & 1,00 \\
\hline Flexibility2 & 14 & 1,50 &, 65 &, 00 & 2,00 \\
\hline Flexibility3 & 14 & 2,50 &, 94 & 1,00 & 4,00 \\
\hline Activitiy1 & 14 &, 50 &, 51 &, 00 & 1,00 \\
\hline Activity2 & 14 & 1,42 &, 51 & 1,00 & 2,00 \\
\hline Activity3 & 14 & 2,35 & 1,00 & 4,00 \\
\hline
\end{tabular}

\section{Level comparative}

A Friedman Test was conducted to compare the significances of scores in the evolution of the two variables into the preintervention and post-intervention (Table 4). The results find significant improvements in children's skills behavior in the two controlled variables over the intervention (posts): Sig=,00 (ChiSquare $=61,21)$. This study revealed, then, that after 2 years of intervention, children's behavior with ASD showed improvement on both analyzed variable

Table 4: Test statistics

\begin{tabular}{|c|c|}
\hline $\mathbf{N}$ & $\mathbf{1 4}$ \\
\hline Chi-Square & 59,56 \\
\hline df & 5 \\
\hline Asymp. Sig. &, 00 \\
\hline
\end{tabular}

\section{Multiple analysis}

The Tests of Between- Subjects Effects was used to compare the results of the Factor 1 variable (interactive scores of the two variables Flexibility 1,2,3 and Activity 1,2,3), as well as the relationships with the variables Diagnosis and Age (Table 5).

Regarding this analysis, the following essential results were analyzed:

a) Concerning pointing the increase in the Factor 1 scores, the results find the significant improvement in intercept source (Between-Subjects Effects: Sig=,00).

b) Multivariate Comparative Test showing a significant interaction the Factor 1 with Diagnosis variable (Sig=,03), which means that changes in Factor 1 are related to the Diagnosis level. However, the Kruskall Wallis Test complemented found interactions only significant in Flexibility 2 (Sig=,01) and Flexibility 3 variable ( $\operatorname{Sig}=, 01$ ), but the results did not find significant interaction to Activity variable (Activity 1: $\operatorname{Sig}=, 46$, Activity 2: Sig= ,10, Activity 3: Sig= ,06).

c) Nevertheless, Between-Subjects Effects found no interactions between the Factor 1 and Age variable (Sig= ,20).

d) Also, it found no significant interaction between Factor 1 and the intersection of Diagnosis - Age (Sig= ,96). e) In summary, our study found general improvement behavior's skills after the program intervention.

f) Graph 1 could be observed the significant improvement achieved by the children during the implementation of the program into Factor 1 (Flexibility= 1-3 sources; Activity= 4-6 sources) to Diagnosis level.

g) Likewise, Graph 2 could be observed the significant improvementachieved by the children during the implementation of the program into Factor 1 (Flexibility= 1- 3 sources; Activity= 4-6 sources) to Age level. Also, development is progressive, but in measure 6 (Activity3), in which a slight setback in the age 1518 years group is indicated.

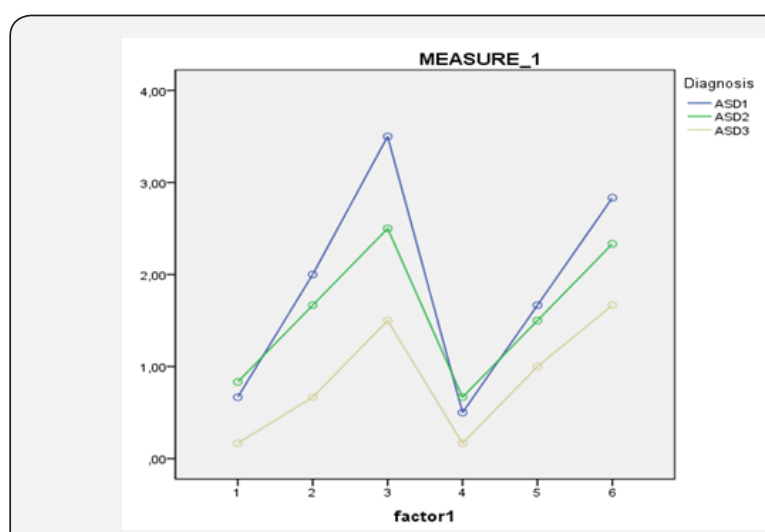

Figure 1: Assessment results of the Factor1 (Flexibility: 1-3, Activity: 4-6) to Diagnosis variable.

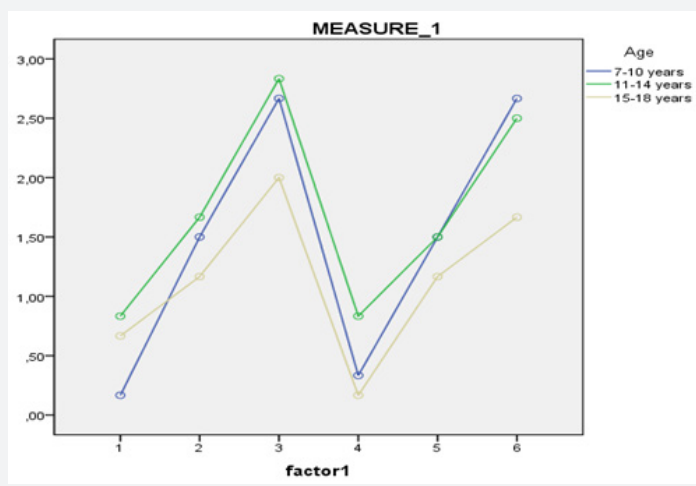

Figure 2: Assessment results of the Factor1 (Flexibility: 1-3, Activity: 4-6) to Age variable. 


\section{Psychology and Behavioral Science International Journal}

Table 5: Tests of Between-Subjects Effects

\begin{tabular}{|c|c|c|c|c|c|}
\hline Source & $\begin{array}{c}\text { Type III Sum of } \\
\text { Squares }\end{array}$ & df & Mean Square & F & Sig. \\
\hline Intercept & 154,00 & 1 & 154,00 & 181,18 &, 00 \\
\hline Diagnosis & 11,77 & 2 & 5,88 & 2,92 &, 03 \\
\hline Age & 3,71 & 2 & 1,85 &, 18 &, 14 \\
\hline Diagnosis* Age &, 47 & 4 &, 12 & & \\
\hline Error & 4,25 & 5 &, 85 & & \\
\hline
\end{tabular}

Measure: MEASURE_1

\section{Discussion}

This program can be considered an effective intervention to promote the development of social skills. Participants have successfully improved behavior performance in the flexibility and functionality tasks. The initial hypothesis has therefore been verified in a pre-post comparative quantitative analysis. The program has improved the level of autonomy in all the participants in the study, with a range of benefits such as achieving better social positive behavior; this is less relevant in the 15-18 years age group, although this does not imply that implementation in older children was not effective. It is therefore important to note that this contribution should be considered in behavior modification programs based on the modeling and stimulus-response perspective [22-23] in order to achieve the following goals:

a) To encourage behavior development by interacting with the cognitive-perceptive system: motivation, emotion, motor or tactile system.

b) To facilitate a diverse repertoire of behaviors in the same learned action, providing greater flexibility and social functionality (activity).

c) To develop social skills (integrated-mediated learning) that is transformed into behavioral alternatives in the environment and replaces disruptive behaviors.

Children with ASD have pragmatic limitations on information perception that involve deficits in the global understanding of perceived stimuli [24-26], meaning programs should facilitate total understanding through the cognitive activation of psycho neurological processes of an integrated and interactive learning method, rather than focusing only on isolated behavior. Achieving this goal requires an intervention protocol based on social mediation between parents-teachers and peers, since support will lead to the basic intervention program, facilitating the development of the programs applied to individuals with ASD in order to improve and increase their behavior skills or repertoires [27-28]. The efficiency of the educational programs intervention support strategy to learn parents-educators and peers support working together to improve of children's developmental. The benefits of the familiar context in which these programs are carried out are particularly notable, allowing children with ASD to play an active part along with other children in a natural family-school interaction context which includes the social mediation model.

Diverse studies [29-31] have defined the social mediation model as an interactive strategy of continuous specific training and an intensive coordination process among those intervening in the natural intervention context: parents-educators and partners. Ojea [32] shows the scientific effectiveness of an applied program for individuals with ASD according to the basic theoretical principles of the social mediation model. The meaning of "social mediation" in this intervention has highlighted the learning perspective and the joint work strategy in relation to the scheduled specific didactic intervention. This study has demonstrated that a mediated program increases intentional social communication and interactions. The design of the mediation social model must therefore include the five well-structured phases [33-37]:

i. $\quad$ Family training based on the aims, spaces, times and methodology of the program.

ii. Training of educators according to the specific intervention process.

iii. Collaboration of peers through cooperative learning strategies.

iv. Coordination of family-educators-peers to organize the programmatic proposals.

v. Ongoing assessment process.

\section{Limitations}

The results of this study should be interpreted with caution due the small sample involved, as common in research into this disorder, especially ASD; however, this does not mean that its conclusions cannot be effective or their outcomes applied in other programs to improve the future of programs designed for people with ASD.

\section{Declaration of conflicting interests}

The authors declare no potential conflicts of interests with respect to the research, authorship and publication of this article.

\section{References}

1. American Psychiatric Association (2013) Diagnostic and statistical manual of mental disorders DSM- $5{ }^{\circledR}\left(5^{\text {th }}\right.$ edn. $)$. American Psychiatric Association, Arlington, Texas, USA.

2. Frith U (2004) Autism: Explaining the enigma. Alianza Editorial Ma- 


\section{Psychology and Behavioral Science International Journal}

drid, Spain.

3. Brandwein AB, Foxe JJ, Butler JS, Frey HP, Bates JC, et al. (2015) Neurophysiological indices of atypical auditory processing and multisensory integration are associated with symptom severity in autism. Journal of Autism and Developmental Disorders 45(1): 230-244.

4. Kimhi Y, Shoam-Kugelmas D, Agam G, Ben-Moshe I, Bauminger-Zviely $\mathrm{N}$ (2014) Theory of mind and executive function in preschoolers with typical development versus intellectually able preschoolers with autism spectrum disorder. Journal of Autism and Developmental Disorders 44(9): 2341-2354.

5. Rossi MR, Vladescu JC, Reeve KF, Gross AC (2017) Teaching safety responding to children with Autism Spectrum Disorder. Education and Treatment of Children 40(2): 187-208.

6. Elliott C, Dillenburger K (2014) The effect of choice on motivation for young children on the Autism Spectrum during discrete trial teaching. Journal of Research in Special Educational Needs, 16(3): 187-198.

7. Vershuur R, Huskens B, Verhoeven L, Didden R (2017) Increasing opportunities for question-asking in school-aged children with Autism Spectrum Disorder: Effectiveness of staff training in pivotal response treatment. Journal of Autism and Developmental Disorders 47(2): 490-505.

8. Ojea M (2017a) Autism Spectrum Disorder: Processing of perceptualcognitive information through the semantic networks learning.

9. Lee J, Vargo KK (2017) Physical activity into socialization: A movement-based social skills program for children with Autism Spectrum Disorder. Journal of Physical Education, Recreation \& Dance 88(4): 7-13.

10. López JM, Moreno-Rodríguez R, Alcover CM, Garrote I, Sánchez S (2017) Effects of a program of sport schools on development of social and psychomotor skills of people with Autistic Spectrum Disorders: A Pilot Project. Journal of Education and Training Studies 5(8): 167-177.

11. Chou W Ch, Lee GT, Feng H (2016) Use of a behavioural art program to improve social skills of two children with Autism Spectrum Disorders. Education and Training in Autism and Developmental Disabilities 51(2): 195-210.

12. Nelson C, Paul K, Johnston SS, Jaimee E (2017) Use of a creative dance intervention package to increase social engagement and play complexity of young children with Autism Spectrum Disorder. Education and Training in Autism and Developmental Disabilities 52(4): 170-185.

13. Bagaiolo LF, Mari JJ, Bordini D, Ribeiro TC, Martone MC, et al. (2017) Procedures and compliance of a video modelling applied behaviour analysis intervention for Brazilian parents of children with Autism Spectrum Disorders. Autism: The International Journal of Research and Practice, 21(5): 603-610.

14. Cardinal JR, Gabrielsen TP, Young EL, Hansen BD, Kellems R, et al. (2017) Discrete trial teaching interventions for students with autism: Web-based video modelling for paraprofessionals. Journal of Special Education Technology 32(3): 138-148.

15. Hughes EM, Yakubova G (2016) Developing handheld video intervention for students with Autism Spectrum Disorder. Intervention in School and Clinic 52(2): 115-121.

16. Andersen ER, Bøttcher L, Dammeyer J (2017) An interview study of why parents conduct intensive ABA home training for their child with Autism Spectrum Disorder. An analysis from the lens of the Dialectical Disability Model. European Journal of Special Needs Education 32(2): 270-286.

17. Blake JM, Rubenstein E, Tsai P Ch, Rahman H, Rieth SR, et al. (2017) Lessons learned while developing, adapting and implementing a pilot parent-mediated behavioural intervention for children with Autism Spectrum Disorder in rural Bangladesh. Autism: The International Journal of Research and Practice 21(5): 611-621.
18. Mahoney G, Solomon R (2016) Mechanism of developmental change in the PLAY Project Home Consultation Program: Evidence from a randomized control trial. Journal of Autism and Developmental Disorders 46(5): 1860-1871.

19. Kossyvaki L, Jones G, Guldbert K (2016) Training teaching staff to facilitate spontaneous communication in children with autism: Adult Interactive Style Intervention (AISI). Journal of Research in Special Educational Needs 16(3): 156-168.

20. Preece D, Symeou L, Stošic J, Troshanska J, Mavrou K, (2016) Accessing parental perspectives to inform the development of parent training in autism in South-Eastern Europe. European Journal of Special Needs Education 32(2): 252-269.

21. Rivière A (1997) Spectrum Autism Inventory (IDEA). In A Rivière, J Martos (Ed.), The Autism treatment, News perspectives, Madrid INSERSO.

22. Bandura A, Ross D, Ross S (1963) Imitation of film-mediated aggressive models. Journal of Abnormal and Social Psychology 66(1): 3-11.

23. Lovaas OI (1987) Behavioral treatment and normal educational and intellectual functioning in young autistic children. Journal of Consulting and Clinical Psychology 55: 3-9.

24. Happe F (1997) Central coherence and theory of mind in autism: reading homographs in context. British Journal of Developmental Psychology 15(1): 1-12.

25. Happe F, Frith U (2006) The weak coherence account: detail-focused cognitive style in autism spectrum disrorders. Journal of Autism and Developmental Disorders 36(1): 5-25.

26. Plaisted K (2001) Reduced generalization in autism: An alternative to weak central coherence. In JA Burack, T Charman, N Yirmiya, PR Zelazo (Edn), The development of autism: Perspectives from theory and research. Erlbaum, pp. 149-169.

27. Adamson LB, Bakeman R, Deckner DF, Romski MA (2009) Joint engagement and the emergence of language in children with autism and Down syndrome. Journal of Autism and Developmental Disorders 39(1): 84-96.

28. Kasari C, Gulsrud AC, Wong C, Know S, Locke J (2010) Randomized controlled caregiver mediated joint engagement intervention for toddlers with autism. Journal of Autism and Developmental Disorders 40(9): 1045-1056.

29. Andersen HM, Nielsen BL (2011) Video based analyses of motivation and interaction in science classrooms. International Journal of Science Education 35(6): 906-928.

30. Cook K, Trepal H, Somody K (2015) Supervision of school counsellors: The SAAFT model. Journal of School Counselling 2015; 10(21): 1-22.

31. Duncan TE, Duncan SC, Strycker LA (2006) An introduction to latent variable growth curve modelling. Concepts, issues, and applications ( $2^{\text {nd }}$ edn.). Lawrence Erlbaum Associates, Mahwah, New Jersey, USA.

32. Schütte K, Köller O (2015) Discover, understand, implement and transfer Effectiveness of an intervention programme to motivate students for science. International Journal of Science Education 37(14): 23062325.

33. Ojea M (2017b) Analysis of the psychoeducational intervention models in students with autism spectrum disorder. Journal of Intellectual Disability, Diagnosis and Treatment 5: 77-84.

34. Brian J, Bernardi K, Dowds E, Easterbrook R, Mac William S, et al. (2017) Feasibility of training early childhood educators in a community child care setting using a caregiver-mediated intervention for toddlers with Autism Spectrum Disorder. Journal of Education and Training Studies 5(5): 93-102.

35. Mc Kee R (2011) Involving your child or teen with ASD in integrated community activities. Exceptional Parent 41(4): 24. 
36. Rice D (2010) Perceptions of trust between professionals and parents of children with autism. California: Pro Quest LLC.

37. Thompson SA (1992) Proposed differentiated service model for community-based consultation organizations and the need for an inter-ministerial integrated service plan for persons with autism in B.C BC Journal of Special Education 16(2): 139-153.
38. Wolfberg P, De Witt M, Young G, Nguyen T (2015) Integrated play groups: Promoting symbolic play and social engagement with typical peers in children with ASD across settings. Journal of Autism and Developmental Disorders 45(3): 830-845.

\section{Your next submission with Juniper Publishers will reach you the below assets}

- Quality Editorial service

- Swift Peer Review

- Reprints availability

- E-prints Service

- Manuscript Podcast for convenient understanding

- Global attainment for your research

- Manuscript accessibility in different formats ( Pdf, E-pub, Full Text, Audio)

- Unceasing customer service

Track the below URL for one-step submission https://juniperpublishers.com/online-submission.php 